\title{
Sexuality of People with Spinal Cord Injury: Knowledge, Difficulties and Adaptation
}

\author{
Simone Beatriz Torriani1, Flavia Costa Britto², Gelson Aguiar da Silva ${ }^{3}$, \\ Deyse Cardoso de Oliveira4, Zuila Maria de Figueiredo Carvalho ${ }^{4}$ \\ ${ }^{1}$ University of the West Regional Hospital, Santa Catarina, Brazil \\ ${ }^{2}$ University of Southern Santa Catarina, Santa Catarina, Brazil \\ ${ }^{3}$ Federal University of Border South UFFS, Santa Catarina, Brazil \\ ${ }^{4}$ Federal University of Ceará, Fortaleza, Ceará, Brazil \\ Email: simonebtorriani@yahoo.com.br, flaviacbritto@gmail.com, gelson.aguiar.ufmt@hotmail.com, \\ deysecard@yahoo.com.br, zmfca@fortalnet.com.br
}

Received 7 April 2014; revised 9 May 2014; accepted 16 May 2014

Copyright (C) 2014 by authors and Scientific Research Publishing Inc.

This work is licensed under the Creative Commons Attribution International License (CC BY).

http://creativecommons.org/licenses/by/4.0/

(c) (i) Open Access

\section{Abstract}

Expressing sexuality is an important part of life, whether the person has a spinal cord injury (SCI) or not. This study investigated the sexual activity before and after SCI, the difficulties, and adjustments made by these people in relation to their sexuality. This is a qualitative study conducted with 14 people with SCI through semi-structured interviews, which we analyzed in light of pertinent literature and organized into three themes: sexual activity before and after SCI; difficulties in performing sexual activities; and adjustments in sexual activity after SCI. We conclude that, although there may be many difficulties, with the partner's support they can get sexual satisfaction and adapt to the new reality. Nonetheless, it is necessary and essential that the patient receive guidance about the possible changes and adaptive methods, and nurses can play a critical role in this process.

\section{Keywords}

Spinal Cord Injuries, Sexuality, Adaptation

\section{Introduction}

The national and international literature defines spinal cord injury as the result of any injury to the neuronal segments, causing sensory and motor damages, represented by functional changes in locomotion, sensitivity, sexuality, and urinary and bowel elimination. These injuries happen most often by firearm injuries, motor vehicle ac- 
cidents, falls, dives, urban violence, and sports injuries, among others [1]-[4].

Sexuality issues are a comprehensive and pervasive theme and cannot be understood only by their genital and biological aspects. Sexuality is expressed in different ways, namely by desires, feelings, thoughts, emotions, attitudes, and behaviors, influenced by cultural context and historical moments [3] [5].

In general, spinal cord injury (SCI) highly influences the sexuality of people affected, and depends on the neurological level and type of injury. The reorganization of sexual expression should be encouraged with regard to sexuality and fertility. Sexual rehabilitation should take place within a holistic perspective, since it contributes to the body self-awareness, sexual satisfaction, and emotional development, hence improving the quality of life of paraplegic or quadriplegic people that present neurogenic sexual dysfunction [1] [6] [7].

The rehabilitation process of people with SCI aims to adapt the individual to their new condition. It is directly associated with improving the quality of life, which takes place through functional independence, improved selfesteem, and social inclusion [8].

Rehabilitation after SCI must promote autonomy and reintegration into the family, social, and work environment, as it is a process of coping with personal difficulties and limitations, encompassing the full reintegration of people with SCI, beyond the experience of sexual health and sexuality [9].

As for the adaptation, we opted for the concept of Callista Roy, which states that humans are biopsychosocial beings in constant interaction with environmental changes and that these systematic actions occur in order to promote adaptive responses in situations of health and illness [10]. This view is consistent with the concept of rehabilitation, because we can promote health by providing adaptive responses of people in situations of health and illness [11].

The adaptation of people with SCI depends on the type of injury and the prognosis; however, other factors such as personality type, educational, social and cultural level, and level of injury also influence it. The knowledge and conception that each person has about sexuality, pleasure, and sex should be considered for the nursing care planning [12].

Nursing care to people with SCI should involve, in addition to clinical competence, the individualized, social, family, and cultural understanding of the individual and the nursing care planning directed to the nursing diagnosis "sexual dysfunction". It must also pay attention to the elaboration of interventions and results focused both on the improvement of sexual performance and prevention of major complications [13] [14].

Given the above, we asked the following questions: Are people with SCI adapted to issues regarding sexuality? Which mechanisms these people use to minimize the difficulties encountered in relation to their sexuality?

The justification for the study is to understand the aspects related to sexuality of people with SCI, regarding the difficulties faced and changes made by these people, in addition to the gap in the literature on the subject. Therefore, we believe that its relevance is centered on the possibility of support nursing care planning in this area as well as believing that nurses must know the experiences and adaptations of people with sexual dysfunction problems, and thus support the practice of neurological nursing.

To answer these questions, we established the following objectives: understand the sexual activity before and after SCI, the difficulties, and the adjustments made by these people in relation to their sexuality.

\section{Methods}

In order to answer our questions, we chose a qualitative approach. The study involved 14 patients with SCI, of both sexes, aged 19 - 63 years, and treated at the Centro Catarinense de Reabilitação (CCR) in Florianopolis, Santa Catarina, Brazil. For the inclusion criteria, we applied: being treated at the rehabilitation clinic in study; older than 18 years; having been diagnosed with upper spinal cord injury for more than 6 months, which we believed to be sufficient for the initial clinical stabilization and for the patient to have had already the opportunity to experience situations related to sexuality after SCI.

Data collection occurred in May 2011 during Complementary Supervised Internship. The data collection instrument consisted of two parts. The first part consisted of characterization data of the subjects, identification variables, clinical data, and closed questions. The second was a questionnaire with three key questions: 1) "How was your relationship with your partner before SCI and how it has being nowadays?”; 2) "What changes or difficulties you think that happened in your sex life?”; and 3) "Can you tell us a bit about how you experience your sexuality today?”. Each interview lasted on average 30 minutes and we recorded the answers in field diaries.

After a thorough reading of the field diaries, we were able to organize the discourses of the research subjects, 
based on the research objectives, allowing identifying three themes: Sexual activity before and after SCI; Difficulties in performing sexual activities; and Adjustments in sexual activity after SCI (Figure 1). We analyzed the findings based on relevant literature. In order to preserve the anonymity, the letter I of interviewees, followed by a number, identifies the statements.

We respected the ethical aspects throughout the study according to the recommendations of Resolution 196/96 of the National Health Council, Brazil [15]. The Research Ethics Committee of the Universidade do Sul de Santa Catarina-Unisul, approved the project under protocol No. 11.090.4.04.III.

\section{Results and Discussion}

Regarding gender, form the 14 participants, there were eleven male and three female. The age ranged from 19 to 63 years. As for the marital status, the majority (eight) were married, five singles, and one widow. As regards education, two patients had completed basic education, five with incomplete basic education, one completed high school, two with incomplete high school, two with complete higher education, and two with incomplete higher education. Wage income ranged from none to more than 5 minimum wages, nine people had income from 2 to 5 minimum wages, four had income greater than 5 minimum wages, and one did not have any income.

Regarding the neurological level of the respondents, six had complete paraplegia, six incomplete paraplegia, and two incomplete tetraplegia. Still on the neurological level, 11 presented injuries of the thoracic level, two cervical, and one lumbar. About the etiology of SCI, seven were victims of automobile accidents, four affected by firearm injuries (FAI), two from Spinal Cord Tumor, and one from complications of Syringomyelia.

Regarding the characterization of the people in study, mostly are men of working age with low income and low education level. The predominance of males confirms the data found in the literature [4] [16]-[18], which is probably because men are more exposed to risk situations and violence.

Likewise, regarding the clinical aspects, these are supported by the literature with the predominance of patients with complete injuries of thoracic level and of traumatic origin [18]-[20].

SEXUAL ACTIVITIES, DIFFICULTIES, AND ADJUSTMENTS.

\subsection{Sexual Activity before and after SCI}

Before SCI there were no problems identified in this field of health, as we can identify in the speeches of two interviewees:

"Good, very good, it was fondly” (I-1).

"Normal, it needed no stimulus" (I-9).

In the sexual activity before SCI, we noted that it was active and referred to as "normal" by most respondents. However, after SCI, six of them were sexually inactive during the research. Some reasons for this isolation might involve the difficulties in establishing emotional relationships and the self-image reorganization after SCI. Disabled people can be seen or see themselves as asexual or uninspiring desire. One possible cause for this affective isolation may be due to prevailing standards of beauty and body aesthetic that can influence the person's experience and body self-awareness, especially among women [1] [3].

In the literature, we also find that the decreased frequency of sexual activity and desire in both male and female and a change in the favorite activities for men and women, because sexual dysfunction can alter the related interests and priorities. Women begin to explore more kisses, hugs, touch, and oral sex, while men tend to prefer kisses and hugs [2]-[22].

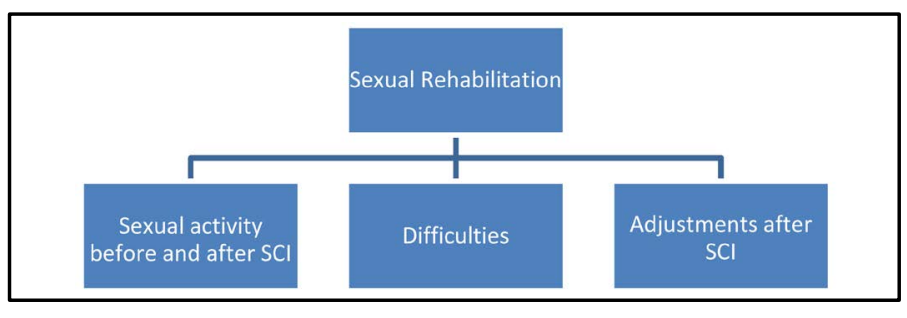

Figure 1. Sexual activities, difficulties, and adjustments. 
Some interviewees reported dissatisfaction with their sexual condition after SCI:

“It got worse, because I depend on her help” (I-3).

"I feel nothing" (I-5).

The impact of SCI on the sexual function depends on its degree and level. Nevertheless, restoring sexual function seems as a main motivation in life to some people, which influences the outcome of rehabilitation. Study on the quality of life of 47 participants with SCI [23] identified the sex life as the worst aspect of satisfaction with $55.3 \%$ of discontent. Physical changes such as sensitivity-related have direct impact on sexual satisfaction, but the authors infer that the influence of psychological factors and social roles such as body image and sexual desire can have a very significant impact on sexuality after SCI [18] [22].

Thus, we verify that the physical consequences are as important as the psychological ones, and the dependence caused by immobility and other complications of SCI, such as neurogenic bladder, bowel dysfunction, spasticity, and pain, are considered possible contributors to sexual dissatisfaction of people with SCI [22]. There is a thin line between the partner's roles, since they also have to be a caregiver, which may influence the way people with SCI see themselves in their limitations and regarding their partner. These perceptions directly affect their self-esteem and interpersonal relationship, because the balance between care dependency and sexual autonomy is often confused with the frequency in social relationships of people with SCI [24].

Another group was seeking information to deal with sexuality after SCI:

“After a lot of reading, I looked for information.” (I-8).

"Eight months ago I started trying to get as close as possible to what it was before." (I-14).

The younger they are at the time of the injury, the more you can expect sexual satisfaction. The search for information on possible changes concerning sexuality after SCI and alternatives to resolve them can alleviate suffering and improve the rehabilitation process [3] [25]. A study conducted with 35 people with SCI, 9 women and 26 men, found that 14 of them had never even touched the subject, nor with health professionals, partners and/or people in similar clinical conditions. Nonetheless, knowledge about sexuality and the process of experimentation and socialization may be vital to the success of love and sex trajectory [9].

\subsection{Difficulties in Sexual Activities}

In the interviewees' statements, we can observe the frequent complaint of erection and ejaculation problems:

"We tried, but we still cannot $\cdots$ the penis does not get 100\% erect." (I-4).

"Having a fixed day and time for preparation, penetration with less time, and without ejaculation" (I-14).

The authors are consensual when mentioning erection and ejaculation as the primary changes found in the sexual function of men with SCI. And for the women, there might be pain with sexual intercourse, dysreflexia, and changes in vaginal lubrication, with absence or reduction of the intensity of orgasm [1] [21] [25].

Penile erection can occur by two mechanisms: reflex erection caused by direct contact on the genitalia, and psychogenic erection, which happens through erotic stimuli. The same goes to vaginal lubrication. The effects on sexual physiology depend on the type, intensity, and degree of SCI, and if the damage to the sacral segments of the column is an upper or lower motor neuron lesion [21].

Another important point with regard to the difficulties presented after SCI concerns the immobility and its consequences:

"In the positions, I used to do whatever I wanted before" (I-5).

"Without the legs, I had to find other positions with the help of my partner to adapt to the new conditions" (I-3).

The changes in mobility may impose limits on sexual activity, due to the decreased capacity of balance and movement of the pelvis during intercourse. Furthermore, if the patient presents muscle tone changes with sudden spasms, positioning for sexual activity may be impaired. Another point to consider is the skin care during intercourse to prevent injuries [21].

Besides the influence of vesico-sphincter changes:

“The accident prevents urinary control and my wife no longer accepts having sexual intercourse” (I-7). 
Due to bladder changes, there are likely to occur urinary loss or accidents at any stage of sexual activity of someone with SCI. These occurrences can negatively impact sexual desire and affective interaction between the couple [21] [25]. Once again, we return to the influence of psychological issues and social roles in the construction of sexual health after SCI. The possibility of urinary and/or fecal accident during sexual activity can greatly affect self-esteem.

The women interviewed in this study did not share if there were changes in vaginal lubrication.

\subsection{Adjustments in Sexual Activity after SCI}

In the speeches, we evidenced as a form of adjustment the change of position for sexual act:

“The partner's assistance, change in sexual positions.” (I-3).

"Now we are trying to improve positions." (I-14).

There are several alternatives to handle sexual dysfunction, depending on the level and extent of injury and the difficulty experienced by the couple. The partner's participation is crucial in the discovery and, if necessary, counseling process. The beginning of the healthy sexual adjustment after SCI, besides adapting the altered physical body, must be linked to the view the patient has on themselves, their sexual self-concept, and what they consider a normal and acceptable behavior in their search for sexual satisfaction, because the psychological, social, and cultural barriers may be as significant as the physical ones [21] [23] [26].

In the speeches, we evidenced as forms of adaptation the change of position for sexual intercourse. This finding, however, contradicts most studies, which state that the most widely used adaptive method is the pharmacological [21] [25] [26].

Partner's support in attitudes towards sexuality, in other words the couples integration, is directly associated with sexual satisfaction. The exploration of new positions, identification of new erogenous zones, and communication between partners are essential for a satisfying sex life. The positioning should take into consideration the balance and skin care, in addition to personal preference [21]. We observe that the first impact of the difficulty created by immobility was also pointed as the best way to achieve satisfaction.

Nevertheless, drug therapy has been cited as a satisfactory option.

"I use medication for erection, we talk a lot" (I-10).

"Nowadays I need medication (for erection).” (I-7).

Regarding the pharmacological method, studies show good responses of penile erection through injection of phosphodiesterase type 5 inhibitors. Whenever the oral therapy is ineffective, intracavernous injection of vasoactive substances such as papaverine, alone or combined with phentolamine and prostaglandin $\mathrm{E}$ may be used. There is also the vacuum penile pump, the cock ring, and ultimately, penile prostheses. For ejaculation and fertility issues, electroejaculation can be a viable alternative. The most appropriate method for each client is determined after considering the risks and benefits, besides the circumstances and interests of the client [21] [25] [26].

Among women, a suggested mechanism is the use of lubricants during sexual intercourse in order to prevent vaginal tearing given the reduced fluids in the vaginal canal [26].

\section{Implications for Research and Neurological Nursing}

Sexuality exists and manifests itself in every human being regardless of having SCI or not. When seeking a health service, people with SCI bring along their sexuality, doubts and questions associated with it. It is fundamental to disseminate information in the prevention, promotion, recovery, and rehabilitation process of people with SCI, as well as regards sexual health.

The nurse, by dealing directly and continuously with the patient, is likely to be the link for this knowledge. However, for this assistance to take place properly, they must have the knowledge and clinical skills necessary for counseling, if the patient so desires. Talking about such an intimate aspect as sexuality also requires the establishment of a respectful relationship and bond between nurse and patient.

\section{Conclusions}

This study aimed to know the sexual activity before and after SCI, the difficulties, and the adjustments made by 
people with SCI in relation to their sexuality.

We were able to observe a considerable level of sexual dissatisfaction after SCI influenced not only by physical changes, but also for issues related to their self-concept and consequences of affective relationships.

We verified that, although there may be many difficulties, with the partner's support they can have sexual satisfaction and adapt to the new reality. Nevertheless, it is essential that the patient receive guidance about the possible changes and adaptive methods because information can effectively contribute to address doubts and reduce fears in the face of the new condition.

Nurses can play a crucial role in this adaptation process, by bonding with their client they may be the link for knowledge and dialogue about sexual health after SCI. At the same time, health care institutions that treat this clientele can offer courses and opportunities for discussion and update on the topic, so that nurses can be up-todate on this important issue.

This study on the sexuality of people with SCI contributes to teaching and research as it addresses an issue that deserves attention from nurses, because it is an important point to consider in the overall health of people.

\section{References}

[1] Magalhães, S., Batista, G., Martin, M. and Pereira, E. (2013) Sexual Dysfunction in Neurogenic Paraplegic-Retrospective Study. Revista da Sociedade Portuguesa de Medicina Física e de Reabilitação, 24, 31-35. http://spmfrjournal.org/index.php/spmfr/article/view/109/85

[2] Carvalho, Z.M.F., Darder, J.J.T., Reis, P.A.M., Magalhães, S.R. and Maniva, S.J.C.F. (2014) Experiencing a Traumatic Spinal Cord Injury-Analysis on the View of the Theory of Watson-s Transpersonal Caring. Journal of Biomedical Science and Engineering, 6, 14-20. http://file.scirp.org/Html/2-9101733_34819.htm

[3] Maia, A.C.B. (2012) Sexuality after Spinal Cord Injury: A Qualitative Analysis of Descriptive Narrative Biographical Interação Psicol, 16, 227-237. http://ojs.c3sl.ufpr.br/ojs-2.2.4/index.php/psicologia/article/view/21212/20279

[4] Rabeh, S.A.N. and Caliri, M.H.L. (2010) Functional Ability in Individuals with Spinal Cord Injury. Acta Paulista de Enfermagem, 23, 321-327. http://www.scielo.br/scielo.php?script=sci arttext\&pid=S0103-21002010000300002

[5] Holanda, K.M.C., Freitas, G.L., Carvalho, Z.M.F. and Barbosa, L.X. (2006) Changes in Sexual Life Carrier SCI. Advances en Enfermería, 24, 23-30. http://www.revistas.unal.edu.co/index.php/avenferm/article/view/35965/37122

[6] Garrett, A. (2012) Impact of Spinal Cord Injury in Affective Relationship: A Qualitative Analysis of the Subjects' Perception. IJFPSS, 2, 1-6. http://fundamentaljournals.org/ijfpss/downloads/9-Garnet\%20260112.pdf

[7] Sodré, P.C. and Faro, A.C.M. (2008) Study of Sexual Function Alterations in Women with Spinal Cord Injuries in the City of Ribeirao Preto, State of São Paulo, Brazil. Acta Fisiatr, 15, 149-155. http://www.actafisiatrica.org.br/detalhe_artigo.asp?id=135

[8] Vall, J., Batista-Braga, V.A. and Almeida, P.C. (2006) Study of the Quality of Life in People with Traumatic Spinal Cord Injury. Arq Neuro Psiquiatr, 64, 451-455. http://www.scielo.br/pdf/anp/v64n2b/a19v642b.pdf

[9] Garrett, A., Martins, F. and Teixeira, Z. (2010) Information and Guidance about Sexuality in Spinal Cord Injury: Perceptions of Patients. Revista da Faculdade de Ciências da Saúde. Edições Universidade Fernando Pessoa, Porto. http://bdigital.ufp.pt/bitstream/10284/2985/3/98-107.pdf

[10] Roy, S.C. (1984) Introduction to Nursing and Adaptation Model. 2nd Edition, Prentice-Hall, Englewood Cliffs.

[11] Vall, J., Lemos, K.I.L. and Janebro, A.S.I. (2014) The Process of Rehabilitation of People with Spinal Cord Injury Based on the Theories of Nursing Vegetable Garden Wanda, Dorothea Orem and Callista Roy: A Theoretical Study. Cogitare Enferm, 10, 63-70. http://ojs.c3sl.ufpr.br/ojs/index.php/cogitare/article/view/5395/3970

[12] Amaral, M.T.P.M. (2009) A New Sense for Living: A Comprehensive Study about the Adaptation Process Following Spinal Cord Injuries. Revista da Escola de Enfermagem da USP, 43, 573-580. http://www.scielo.br/pdf/reeusp/v43n3/en_a11v43n3.pdf

[13] Cavalcante, K.M.H., Carvalho, Z.M.F. and Garcia, F.M.P. (2014) Nursing Diagnoses Applicable to Persons with Paraplegia in the Initial Phase of Home Rehabilitation. Rev Enferm UFSM, 3, 238-247. http://cascavel.ufsm.br/revistas/ojs-2.2.2/index.php/reufsm/article/view/7897/pdf

[14] Pantaroto, H.S.C. and Santos, L.C.R. (2006) Vesico-Sphincter Dysfunction: Adaptations Made by Quadriplegics and Caregivers Guidelines of Nurses. Review of Estima, 4, 18-22.

http://www.revistaestima.com.br/index.php?option=com_content\&view=article\&id=228\%3Aartigo-original-1\&catid= 34\%3Avol-4-edicao-4-outnovdez-2006\&Itemid=72\&lang=pt

[15] Brasil. Ministério da Saúde (1996) Conselho Nacional de Saúde. Resolução no 196/96. Decreto no 93.933 de janeiro de 1987. Establishes Criteria for Research Involving Humans. Bioética, 4, 15-25. 
[16] Silva, G.A., Schoeller, S.D., Gelbcke, F.L., Carvalho, Z.M.F. and Silva, E.M.J.P. (2014) Functional Assessment of Persons with Spinal Cord Injury: Using the Scale of Functional Independence-MIF. Texto Contexto Enferm, 21, 929936. http://www.scielo.br/pdf/tce/v21n4/25.pdf

[17] Medola, F.O., Busto, R.M., Marçal, A.F., Achour Jr., A. and Dourado, A.C. (2011) The Sport on Quality of Life of Individuals with Spinal Cord Injury: A Case Series. Revista Brasileira de Medicina do Esporte, 17, 254-256. http://www.scielo.br/pdf/rbme/v17n4/v17n4a08.pdf

[18] França, I.S.X., Coura, A.S., Sousa, F.S., Almeida, P.C. and Pagliuca, L.M.F. (2014) Quality of Life in Patients with Spinal Cord Injury. Rev Gaúcha Enferm, 34, 155-163. http://seer.ufrgs.br/index.php/RevistaGauchadeEnfermagem/article/view/23392/24525

[19] Brito, M.A.G.M., Bachion, M.M. and Souza, J.T. (2014) Nursing Diagnoses of Most Incidence on People with Spinal Cord Injury in the Context of Outpatient Care through an Approach Based on Orem Theory. Revista Eletrônica de Enfermagem, 10, 13-28. http://www.fen.ufg.br/fen_revista/v10/n1/pdf/v10n1a02.pdf

[20] Bampi, L.N.S., Guilhem, D. and Lima, D.D. (2008) Quality of Live in People with Traumatic Spinal Cord Injury: A Study with Whoqol-Bref. Revista Brasileira de Epidemiologia, 11, 67-77. http://www.scielo.br/pdf/rbepid/v11n1/06.pdf

[21] Ricciardi, R., Szabo, C.M. and Poullos, A.Y. (2014) Sexuality and Spinal Cord Injury. Nursing Clinics of North America, 42, 675-684. http://www.researchgate.net/publication/5849680

[22] Reitz, A., Tobe, V., Knapp, P.A. and Schurch, B. (2004) Impact of Spinal Cord Injury on Sexual Health and Quality of Life. International Journal of Impotence Research, 16, 167-174. http://www.nature.com/ijir/journal/v16/n2/pdf/3901193a.pdf

[23] França, I.S.X., Coura, A.S., França, E.G., Basílio, N.N.V. and Souto, R.Q. (2014) Quality of Life of Adults with Spinal Cord Injury: A Study Using the Whoqol-Bref. Revista da Escola de Enfermagem da USP, 45, 1364-1371. http://www.scielo.br/pdf/reeusp/v45n6/v45n6a13.pdf

[24] Schoeller, S.D., Bitencourt, R.N., Leopardi, M.T., Pires, D.P. and Zanini, M.T.B. (2012) Changes in the Life of People with Acquired Spinal Cord Injury. Revista Eletrônica de Enfermagem, 14, 95-103. http://www.fen.ufg.br/fen revista/v14/n1/pdf/v14n1a11.pdf

[25] Biering-Sørensen, I., Hansen, R.B. and Biering-Sørensen, F. (2012) Sexual Function in a Traumatic Spinal Cord Injured Population 10 - 45 Years after Injury. Journal of Rehabilitation Medicine, 44, 926-931. http://www.medicaljournals.se/jrm/content/?doi=10.2340/16501977-1057\&html=1

[26] Cavalcante, K.H., Carvalho, Z.M.F., Barbosa, I.V. and Rolim, G.A. (2008) Experience of the Sexuality by People with Spinal Cord Injury. Review of RENE, 9, 27-35. http://www.revistarene.ufc.br/revista/index.php/revista/article/view/515 